\title{
The risk and burden of vertebral fractures in Sweden
}

\author{
J.A. Kanis $\cdot$ O. Johnell $\cdot$ A. Oden $\cdot$ F. Borgstrom \\ N. Zethraeus $\cdot$ C. De Laet $\cdot$ B. Jonsson
}

Received: 11 March 2003/ Accepted: 23 May 2003 / Published online: 31 October 2003

(C) International Osteoporosis Foundation and National Osteoporosis Foundation 2003

\begin{abstract}
The aim of this study was to determine the risk and burden of vertebral fractures judged as those coming to clinical attention and as morphometric fractures. Incidence and utility loss were computed from data from Malmo, Sweden. Clinical fractures accounted for $23 \%$ of all vertebral deformities in women and for $42 \%$ in men. The average 10-year fracture probability for morphometric fractures increased with age in men from $2.9 \%$ at the age of 50 years $(7.2 \%$ in women) to 8.4 at the age of 85 years $(26.7 \%$ in women). As expected, probabilities increased with decreasing T-score for hip BMD. Cumulative utility loss from a clinical vertebral fracture was substantial and was $50-62 \%$ of that due to a hip fracture depending on age. When incidence of fractures in the population was weighted by disutility, all spine fractures accounted for more morbidity than hip fracture up to the age of 75 years. We conclude that vertebral fractures have a major personal and societal impact that needs to be recognised in algorithms for assessment of risk and in health economic strategies for osteoporosis.
\end{abstract}

Keywords Burden of fracture - Osteoporotic fracture · Utility $\cdot$ Vertebral fracture

\footnotetext{
J.A. Kanis $(\square)$

Centre for Metabolic Bone Diseases (WHO Collaborating Centre), University of Sheffield Medical School,

Beech Hill Road, Sheffield, S10 2RX, UK

Tel.: + 44-114-2851109

Fax: + 44-114-2851813

O. Johnell

Department of Orthopaedics, Malmo General Hospital, Malmo, Sweden
}

\author{
A. Oden \\ Consulting Statistician, Gothenburg, Sweden \\ F. Borgstrom · N. Zethraeus $\cdot$ B. Jonsson \\ Department of Economics, Stockholm School of Economics, \\ Stockholm, Sweden \\ C. De Laet \\ Department of Public Health, Erasmus Medical Center, \\ 3000 DR Rotterdam, The Netherlands
}

\section{Introduction}

We have previously characterised the morbidity in the population of Sweden that arises from osteoporotic fractures. In that study fracture risk was weighted according to the morbidity associated with each osteoporotic fracture [1]. The unit of morbidity used was the cumulative loss of quality of life (disutility). The purpose was to devise a methodology to compute intervention thresholds where the multiple outcomes of different fractures and the different consequences were reduced to a single metric. Since then data have become available that suggest that the incidence and consequences of vertebral fracture may have been considerably underestimated. Whereas our previous study focused on the probability of a clinical vertebral fracture and its attendant morbidity, it is now evident that morphometric fractures that do not come to clinical attention have significance, since they are not all asymptomatic [2,3]. Moreover, the risk of further fractures is increased [4]. With respect to clinical fractures, recent estimates suggest that the loss of quality of life is very significant, and far greater than hitherto appreciated $[5,6,7,8]$. Indeed, the loss of quality of life in the 1st year after clinical fracture may be of the same order of magnitude as that for a hip fracture [9].

The aim of the present study was to determine the risk of both morphometric and clinically diagnosed fractures. For this purpose the first vertebral fracture was documented so that 10 -year probabilities of fracture could be computed. A further aim was to characterise the burden of both morphometric and clinical fractures as judged by cumulative disutility.

\section{Materials and methods}

Incidence of vertebral fracture

Vertebral fractures may be clinically overt (i.e., coming to clinical attention), clinically silent or asymptomatic. Collectively, they are termed morphometric fractures. For the purposes of this paper we 
wished to estimate the incidence burden and long-term probability of both morphometric fractures and clinical fractures. A clinical fracture in this context is one that comes to hospital attention through in-patient or outpatient attendance or one diagnosed radiographically by the general practitioner.

For the incidence of clinically diagnosed vertebral fracture we used data from Malmo 1993/1994 [10], and a Poisson model was used to smooth the published function with age. For the incidence of morphometric fractures we computed the incidence in Europe from the EVOS/EPOS [11] and the Rotterdam study [12]. Both studies measured morphometric deformities prospectively using an identical algorithm [13]. A Poisson model was used to estimate the incidence of morphometric fractures in the two studies. The unweighted $\beta$ coefficients (i.e., unweighted by sample size) were used to merge the data and compute the incidence in Europe. The incidence was revised upward to take account of the higher age and sex-specific incidence in Sweden compared with rates in Europe [11]. For men, rates were multiplied by 1.28 and for women by 1.654. These estimates together with the disutility (see later) were used to determine the burden of vertebral fractures at specific ages in both men and women.

For the computation of the probability of a first vertebral fracture, it was necessary to determine the incidence of a first vertebral fracture. In the case of clinically diagnosed fractures, this has previously been assessed directly from patients in Malmo [10] by accessing the in-patient, out-patient and radiology records from 1993 and 1994. Patients with prior vertebral fractures were excluded to compute incidence of a first vertebral fracture. The ratio of the incidence of a first fracture to the unadjusted incidence of vertebral fracture was 0.75 in men and 0.73 in women, and relatively constant with age. In the Rotterdam study, the estimate is very similar for morphometric fractures, being 0.79 in men and 0.69 in women [12]. For the present purposes we took the ratio of 0.74 and assumed that the same ratio was also applicable to morphometric fractures. For comparative purposes we used data on the incidence of hip and other osteoporotic fractures from a previous publication [1].

\section{Probability of fracture}

The 10-year probability of vertebral fracture was calculated using a Poisson model from the incidence of the first fracture with age and the mortality estimates by age in 5-year intervals. Vertebral fractures included those coming to clinical attention and all morphometric fractures. The 10-year probabilities were computed by previously published methods from the hazard of first fracture and the death hazard $[14,15]$.

In order to determine the fracture probability according to BMD, we used the published data from the 3rd National Health and Nutrition Examination Survey (NHANES III, 1998-1994) as the reference values for BMD at the femoral neck [16]. Cut off values to categorize individuals as having low bone mass or osteoporosis utilised the WHO criteria, so that osteoporosis was defined as a T-score of $<-2.5 \mathrm{SD}$ and low bone mass denoted a T-score of -1 to $-2.5 \mathrm{SD}$ [17]. Cut-off values were chosen in young women based on the age range 20-29 years. The threshold for low bone mass was $0.740 \mathrm{~g} / \mathrm{cm}^{2}$ and $0.577 \mathrm{~g} / \mathrm{cm}^{2}$ for osteoporosis. We chose the same thresholds for men since the incidence of hip and vertebral fracture in men is similar to that in women for the same BMD [18, 19, 20, 21, 22]. The risk of fracture at the spine was assumed to increase 1.8 -fold for each standard deviation decrease in bone mineral density (95\% CI 1.1-2.7), as estimated by a previous meta-analysis [23]. Probability by age was expressed as the risk of an individual at a given T-score for BMD [14].

\section{Quality of life}

Quality of life following a clinical vertebral fracture was taken from a study in which this was assessed prospectively in 40 patients attending the Accident and Emergency Department at Malmo $[7,9]$. The EQ-5D was administered at 14 days and 6, 9 and 12 months after the fracture event. Each patient was asked to fill in the questionnaire on the health status experienced at the time of the interview. Interviews were conducted in 43 patients at week 2 , and complete information obtained on 40 patients. The EQ-5D was also administered to 86 patients with hip fracture, 126 patients with a distal forearm fracture and 40 patients with a fracture at the proximal humerus.

Health state values obtained from areas under the curve with time did not differ between men and women, but decreased somewhat with age. Age and sex-specific social tariff values for Sweden [24] were used to calculate the utility loss associated with each fracture type. For a clinical vertebral fracture this was a loss of 0.260 , which was greater than that for hip fracture (0.149), fracture of the proximal humerus (0.153) and forearm fracture (0.017). Age and specific utility losses were used to compute the multiplier that could be used to determine utility losses for vertebral fracture and other fracture types at any age (Table 1).

The utility losses for vertebral fracture obtained above were those coming to clinical attention. The utility loss after a morphometric deformity not coming to clinical attention is not known. Patients with sub-clinical fracture are reported to have impaired activities of daily living (ADLs) that are about one-third to one-half of the ADLs in patients with a clinical fracture $[2,3]$ On this basis we assumed that the utility loss of a sub-clinical fracture was one-third that of a clinically overt fracture, since a proportion of the decrement observed may have resulted from co-morbidity. From the ratio of clinical to non-clinical fractures $(42 \%$ in men and $23 \%$ in women), the utility loss from all vertebral fractures was calculated for the 1 st year. In men, this was:

$(0.42 \times 0.260)+(0.58 \times 0.260 / 3)=0.159$

This gave a multiplier of 0.777 in men for the 1 st year.

In women, the utility loss in the 1 st year was:

$(0.22 \times 0.260)+(0.78 \times 0.260 / 3)=0.125$

This gave a multiplier of 0.820 .

For the quality of life in the 2nd year after a clinical fracture we used a multiplier of 0.909 (a utility loss of 0.100 ), calculated from a case control study of patients enrolled into the MORE study with vertebral fractures (both symptomatic and asymptomatic) [25]. Fracture occurred at an unknown time prior to assessment. The value closely matches unpublished information from the CaMos study in Canada (A Tenenhouse, personal communication, 2002). We assumed that the utility loss in the 2 nd year after a non-clinical morphometric fracture was one-third that of a clinical fracture. Thus, for the second year after a fracture (clinical and non-clinical) the utility loss in men was:

$(0.42 \times 0.1)+(0.58 \times 0.033)=0.061$

This gave a multiplier of 0.912 .

Table 1 Health state utility values according to site of fracture

\begin{tabular}{|c|c|c|c|c|}
\hline \multirow[t]{2}{*}{ Fracture site } & \multicolumn{2}{|c|}{$\begin{array}{l}\text { Multiplier for } \\
\text { utility }\end{array}$} & \multicolumn{2}{|c|}{$\begin{array}{l}\text { Multiplier for } \\
\text { utility loss }\end{array}$} \\
\hline & $\begin{array}{l}1 \text { st } \\
\text { year }\end{array}$ & $\begin{array}{l}\text { 2nd } \\
\text { year }\end{array}$ & $\begin{array}{l}1 \text { st } \\
\text { year }\end{array}$ & $\begin{array}{l}\text { 2nd } \\
\text { year }\end{array}$ \\
\hline Spine (clinical) & 0.626 & 0.909 & 0.374 & 0.091 \\
\hline $\begin{array}{l}\text { Spine (all morphometric) } \\
\text { men }\end{array}$ & 0.777 & 0.912 & 0.223 & 0.088 \\
\hline $\begin{array}{l}\text { Spine (all morphometric) } \\
\text { women }\end{array}$ & 0.820 & 0.913 & 0.180 & 0.087 \\
\hline Ribs & 0.977 & 0.999 & 0.003 & 0.001 \\
\hline Pelvis & 0.794 & 0.815 & 0.206 & 0.185 \\
\hline Humerus & 0.794 & 0.973 & 0.206 & 0.027 \\
\hline Clavicle, scapula, sternum & 0.977 & 0.999 & 0.003 & 0.001 \\
\hline Hip & 0.792 & 0.813 & 0.208 & 0.187 \\
\hline Other femoral & 0.792 & 0.813 & 0.208 & 0.187 \\
\hline Tibia & 0.794 & 0.926 & 0.206 & 0.074 \\
\hline Forearm & 0.977 & 0.999 & 0.003 & 0.001 \\
\hline
\end{tabular}


In women the loss was:

$(0.22 \times 0.1)+(0.78 \times 0.033)=0.048$

This gave a multiplier of 0.931 for the 2 nd year in women.

For comparative purposes the utility loss for hip fracture, distal forearm fracture and fractures of the proximal humerus were taken from the study above. The utility loss after a rib, scapular, clavicular and sternal fracture was assumed to be similar to that of a distal forearm fracture $[1,26]$. Femoral fractures other than the hip had a loss equivalent to a hip fracture. For pelvic and leg fractures the utility loss was equivalent to a humeral fracture as previously assumed [1].

The quality of life in the 2nd year after a fracture varied according to fracture type. For hip fracture this was assumed to be $90 \%$ of that of a healthy individual [27, 28], and the same assumptions were used for other femoral fractures and for pelvic fractures. For other sites of fracture, health state values were assumed to improve after the 1st year by a proportion equal to that previously assumed by the NOF [26] and by ourselves [1]. Health state utility values are given in Table 1 for each fracture site.

\section{Burden of vertebral fracture}

Loss of utilities after the 2nd and subsequent year were assumed to decrease by $10 \%$ per year. The cumulative loss of utility (disutility) was calculated for each age and fracture in men and women over the remaining life-time. These disutilities were then weighted by the social tariff values for each and sex and used to calculate the incidence-adjusted morbidity, as previously described [1].

\section{Results}

\section{Incidence of fracture}

The incidence of all morphometric and clinical vertebral fractures by age and sex is shown in Table 2 . The ratio of clinical to morphometric fractures was higher in men than in women and in both sexes increased slightly with age. Approximately $42 \%$ of vertebral fractures in men came to clinical attention, and in women the proportion was $22 \%$.

Ten-year vertebral fracture probability

The average 10-year probability of morphometric and clinical spine fractures is shown in Table 3. As expected,
Table 3 Average 10-year probability (\%) of vertebral fracture according to age

\begin{tabular}{llllll}
\hline Age (years) & \multicolumn{2}{l}{$\begin{array}{l}\text { Morphometric } \\
\text { spine fracture }\end{array}$} & & \multicolumn{2}{l}{$\begin{array}{l}\text { Clinical spine } \\
\text { fracture }\end{array}$} \\
\cline { 2 - 3 } \cline { 5 - 6 } & Men & Women & & Men & Women \\
\hline 50 & 2.9 & 7.2 & & 1.1 & 1.4 \\
55 & 3.7 & 9.4 & & 1.5 & 2.0 \\
60 & 4.6 & 12.3 & & 1.9 & 2.8 \\
65 & 5.6 & 15.9 & & 2.5 & 3.8 \\
70 & 6.8 & 20.1 & & 3.2 & 5.1 \\
75 & 7.8 & 24.2 & & 3.8 & 6.4 \\
80 & 8.5 & 26.8 & & 4.2 & 7.4 \\
85 & 8.4 & 26.7 & 4.3 & 7.5 \\
\hline
\end{tabular}

probabilities of morphometric fractures were substantially higher than for clinical fractures, and both increased with age up to the age of 80 years. Thereafter, the 10-year probability plateaued or decreased because of the competing effects of fracture and death hazards. As expected, probabilities were higher in women than in men.

The probability of vertebral fracture by age, sex and T-score is shown in Fig. 1. Fracture probabilities increased with decreasing T-score and increasing age, up to the age of 70 years. Above this age, probabilities plateaued or decreased slightly (Tables 4 and 5). Thus, up to the age of 70 years, age provided an independent element of risk not captured by BMD. Over a 4-SD interval of BMD $(+1$ to $-3 \mathrm{SD})$, the risk of a vertebral fracture increased approximately 9-fold in men and 12fold in women.

\section{Disutility}

The cumulative loss of utility (disutility) due to fractures of different types is shown in Table 6 by age and sex. As expected, average disutility was greatest in the case of hip fractures over all ages, intermediate for vertebral fractures and lower for humeral and Colles' fracture. Disutility values were higher in the younger age groups due to the higher life expectancy and higher population tariff values. The higher tariff values for the younger healthy population and the use of a multiplier to compute disutility mean that the absolute (rather than
Table 2 Incidence of all morphometric and clinically evident vertebral fractures and the first morphometric and clinical fracture (per 100,000 per year) by age in men and women

\begin{tabular}{|c|c|c|c|c|c|c|c|c|c|c|}
\hline \multirow[t]{3}{*}{ Age range (years) } & \multicolumn{4}{|c|}{ Any fracture } & \multicolumn{4}{|c|}{ First fracture } & \multirow{2}{*}{\multicolumn{2}{|c|}{$\begin{array}{l}\text { Ratio }(\%) \\
\text { Clinical/ } \\
\text { morphometric }\end{array}$}} \\
\hline & \multicolumn{2}{|c|}{ Morphometric } & \multicolumn{2}{|c|}{ Clinical } & \multicolumn{2}{|c|}{ Morphometric } & \multicolumn{2}{|c|}{ Clinical } & & \\
\hline & Men & Women & Men & Women & Men & Women & Men & Women & Men & Women \\
\hline $50-54$ & 365 & 874 & 153 & 190 & 244 & 577 & 81 & 104 & 33 & 19 \\
\hline $55-59$ & 462 & 1,164 & 193 & 253 & 311 & 762 & 111 & 148 & 36 & 20 \\
\hline $60-64$ & 592 & 1,562 & 248 & 339 & 392 & 1,021 & 155 & 215 & 39 & 21 \\
\hline $65-69$ & 767 & 2,115 & 322 & 459 & 511 & 1,376 & 215 & 303 & 42 & 22 \\
\hline $70-74$ & 1,011 & 2,891 & 424 & 628 & 666 & 1,880 & 296 & 422 & 44 & 23 \\
\hline $75-79$ & 1,348 & 3,986 & 566 & 865 & 888 & 2,583 & 407 & 599 & 46 & 23 \\
\hline $80-84$ & 1,820 & 5,544 & 744 & 1,204 & 1,191 & 3,574 & 562 & 844 & 47 & 24 \\
\hline $85-89$ & 2,485 & 7,776 & 1,043 & 1,688 & 1,613 & 4,995 & 777 & 1,184 & 48 & 24 \\
\hline
\end{tabular}


Fig. 1 Ten-year probabilities (\%) of a morphometric or clinical vertebral fracture in men and women by T-score and age
Probability ( $\%$ at 10 years)

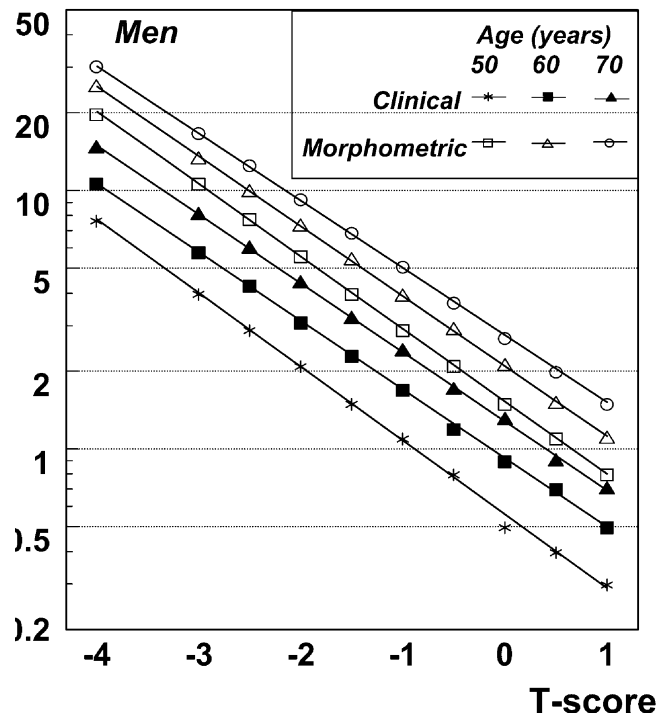

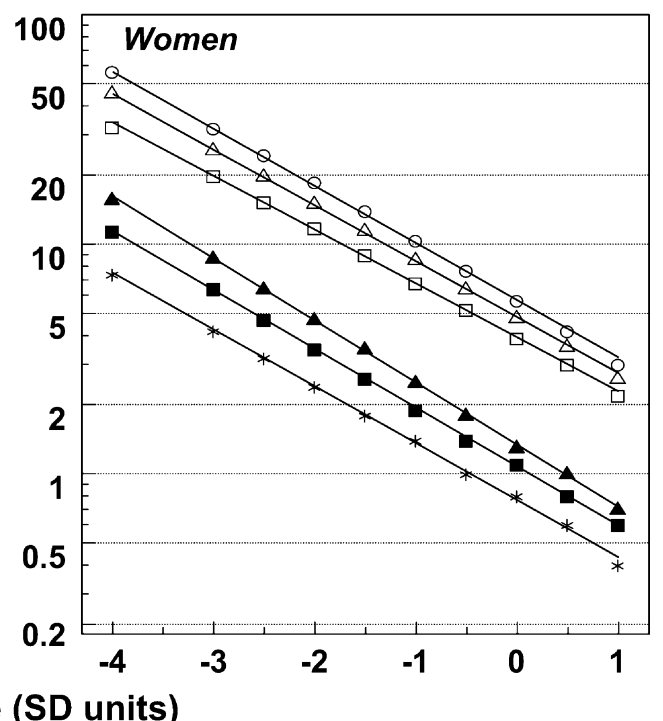

Table 4 Ten-year probability of vertebral fracture according to age and $\mathrm{T}$-score at the femoral neck in men

\begin{tabular}{llllllllllll}
\hline \multicolumn{2}{l}{ T-score (SD units) } \\
\hline \multicolumn{1}{l}{ Age (years) } & +1 & +0.5 & 0 & \multicolumn{1}{l}{-0.5} & -1.0 & -1.5 & -2.0 & -2.5 & -3.0 & -4.0 \\
\hline \multicolumn{2}{l}{ (a) Morphometric } \\
45 & 0.7 & 0.9 & 1.3 & 1.8 & 2.4 & 3.4 & 4.6 & 6.4 & 8.7 & 16.1 \\
50 & 0.8 & 1.1 & 1.5 & 2.1 & 2.9 & 4.0 & 5.6 & 7.8 & 10.7 & 19.9 \\
55 & 0.9 & 1.2 & 1.7 & 2.4 & 3.4 & 4.7 & 6.6 & 9.2 & 12.8 & 24.0 \\
60 & 1.1 & 1.5 & 2.1 & 2.9 & 3.9 & 5.4 & 7.3 & 9.9 & 13.3 & 23.5 \\
65 & 1.5 & 2.0 & 2.6 & 3.5 & 4.6 & 6.2 & 8.1 & 10.7 & 14.1 & 23.8 \\
70 & 1.5 & 2.0 & 2.7 & 3.7 & 5.1 & 6.9 & 9.3 & 12.6 & 16.8 & 28.9 \\
75 & 1.4 & 1.9 & 2.7 & 3.8 & 5.3 & 7.4 & 10.3 & 14.1 & 19.3 & 34.0 \\
80 & 1.6 & 2.2 & 2.9 & 3.9 & 5.3 & 7.1 & 9.5 & 12.7 & 16.8 & 28.1 \\
85 & 1.7 & 2.2 & 2.9 & 3.8 & 4.9 & 6.4 & 8.4 & 10.8 & 14.0 & 22.6 \\
(b) Clinical & & & & & & & & & & \\
45 & 0.2 & 0.3 & 0.4 & 0.6 & 0.8 & 1.1 & 1.5 & 2.1 & 3.0 & 5.6 \\
50 & 0.3 & 0.4 & 0.5 & 0.8 & 1.1 & 1.5 & 2.1 & 2.9 & 4.0 & 7.7 \\
55 & 0.3 & 0.5 & 0.7 & 0.9 & 1.3 & 1.9 & 2.7 & 3.7 & 5.3 & 10.3 \\
60 & 0.5 & 0.7 & 0.9 & 1.2 & 1.7 & 2.3 & 3.1 & 4.3 & 5.8 & 10.7 \\
65 & 0.7 & 0.9 & 1.2 & 1.6 & 2.1 & 2.8 & 3.7 & 4.9 & 6.5 & 11.4 \\
70 & 0.7 & 0.9 & 1.3 & 1.7 & 2.4 & 3.2 & 4.4 & 6.0 & 8.1 & 14.7 \\
75 & 0.7 & 0.9 & 1.3 & 1.8 & 2.5 & 3.6 & 5.0 & 7.0 & 9.7 & 18.3 \\
80 & 0.8 & 1.1 & 1.4 & 1.9 & 2.6 & 3.5 & 4.8 & 6.4 & 8.6 & 15.2 \\
85 & 0.9 & 1.1 & 1.4 & 1.9 & 2.5 & 3.2 & 4.2 & 5.5 & 7.2 & 12.2 \\
\hline
\end{tabular}

proportional) utility loss after fracture is higher in younger individuals. The consideration of all vertebral fractures rather than clinical spine fractures alone decreased the average disutility of vertebral fractures by $15-30 \%$ depending on age. At the age of 50 years, a clinical spine fracture incurred a disutility of $62 \%$ of that for a hip fracture in men and women, and was substantially higher than the loss incurred from humeral fractures by $63 \%$.

The overall burden of vertebral fracture is compared with incidence in Table 7. In men at the age of 50 years, clinical fractures accounted for $18 \%$ of osteoporotic fractures between the ages of 50 and 55 years, but for
Table 5 Ten-year probability of vertebral fracture according to age and $\mathrm{T}$-score at the femoral neck in women

T-score (SD units)

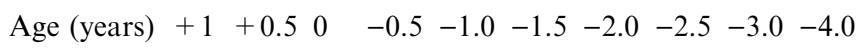

(a) Morphometric

\begin{tabular}{|c|c|c|c|c|c|c|c|c|c|c|}
\hline 45 & 2.1 & 2.7 & 3.6 & & 6.0 & 7.8 & 10.1 & 12.9 & 16.6 & 26.7 \\
\hline 50 & 2.2 & 3.0 & 3.9 & 5.2 & 6.8 & 9.0 & 11.8 & 15.3 & 19.9 & 32.5 \\
\hline 55 & 2.3 & 3.1 & 4.1 & 5.5 & 7.5 & 10.0 & 13.3 & 17.6 & 23.2 & 38.5 \\
\hline 60 & 2.6 & 3.6 & 4.8 & 6.4 & 8.6 & 11.5 & 15.1 & 19.9 & 25.9 & 42.2 \\
\hline 65 & 3.1 & 4.2 & 5.6 & 7.4 & 9.9 & 13.1 & 17.2 & 22.3 & 28.9 & 45.9 \\
\hline 70 & 3.0 & 4.2 & 5.7 & 7.7 & 10.4 & 14.0 & 18.7 & 24.6 & 32.1 & 51.3 \\
\hline 5 & 2.7 & 3.8 & 5.3 & 7.4 & 10.2 & 14.1 & 19.1 & 25.6 & 33.8 & 54.5 \\
\hline & 2.8 & 3.9 & 5.4 & 7.4 & 10.2 & 14.0 & 18.8 & 24.9 & 32.6 & 51.6 \\
\hline & 2.6 & 3.6 & 5.0 & 6.8 & 9.2 & 12.5 & 16.7 & 22.0 & 28.7 & 5.4 \\
\hline \multicolumn{11}{|l|}{ (b) Clinical } \\
\hline & 0.4 & 0.5 & 0.6 & 0.8 & 1.1 & 1.4 & 1.9 & 2.4 & 3.2 & 5.4 \\
\hline & 0.4 & 0.6 & 0.8 & 1.0 & 1.4 & 1.8 & 2.4 & 3.2 & 4.2 & 7.4 \\
\hline & 0.5 & 0.6 & 0.9 & 1.2 & 1.6 & 2.2 & 3.0 & 4.0 & 5.4 & 9.7 \\
\hline & 0.6 & 0.8 & 1.1 & 1.4 & 1.9 & 2.6 & 3.5 & 4.7 & 6.4 & 11.4 \\
\hline & 0.7 & 1.0 & 1.3 & 1.7 & 2.3 & 3.1 & 4.2 & 5.6 & 7.5 & 13.1 \\
\hline & 0.7 & 1.0 & 1.3 & 1.8 & 2.5 & 3.5 & 4.7 & 6.4 & 8.7 & 15.7 \\
\hline & 0.7 & 0.9 & 1.3 & 1.8 & 2.5 & 3.5 & 4.9 & 6.8 & 9.5 & 17.8 \\
\hline & 0.7 & 1.0 & 1.3 & 1.9 & 2.6 & 3.6 & 4.9 & 6.8 & 9.3 & 17.3 \\
\hline & 0.7 & 0.9 & 1.3 & 1.7 & 2.3 & 3.2 & 4.4 & 6.0 & 8.2 & 14.9 \\
\hline
\end{tabular}

$51 \%$ of the total morbidity. With advancing age the morbidity from clinical vertebral fractures exceeded that for hip fracture until after the age of 64 years. When morphometric fractures are considered these comprised, as expected, a higher proportion of the total number of fractures, and because of the additional consequences for morbidity, the population morbidity from morphometric spinal fractures exceeded that of hip fracture until after the age of 75 years.

The results were qualitatively similar for women except where morphometric fractures are concerned. These accounted for a greater proportion of the total number of fractures since a greater number of morphometric 
Table 6 Disutility for different fracture types by age adjusted for the population tariffs using a discount of $10 \%$ per annum

\begin{tabular}{|c|c|}
\hline \multirow{2}{*}{$\begin{array}{l}\text { Type of } \\
\text { fracture }\end{array}$} & Age range (years) \\
\hline & $50-5455-5960-6465-6970-7475-7980-8485-89$ \\
\hline
\end{tabular}

(a) Men

Morphometric $\begin{array}{llllllll}0.877 & 0.800 & 0.757 & 0.713 & 0.714 & 0.557 & 0.420 & 0.350\end{array}$ spine

$\begin{array}{lllllllll}\text { Clinical spine } & 1.026 & 0.938 & 0.895 & 0.850 & 0.768 & 0.687 & 0.538 & 0.472\end{array}$

$\begin{array}{llllllllll}\text { Humerus } & 0.383 & 0.353 & 0.339 & 0.327 & 0.301 & 0.277 & 0.228 & 0.212\end{array}$

$\begin{array}{llllllllll}\text { Hip } & & 1.643 & 1.491 & 1.402 & 1.304 & 1.148 & 0.980 & 0.701 & 0.943\end{array}$

$\begin{array}{lllllllll}\text { Forearm } & 0.010 & 0.009 & 0.009 & 0.009 & 0.008 & 0.007 & 0.005 & 0.005\end{array}$

(b) Women

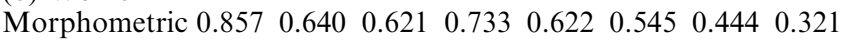
spine

$\begin{array}{lllllllll}\text { Clinical spine } & 1.053 & 0.751 & 0.734 & 0.917 & 0.790 & 0.706 & 0.594 & 0.460\end{array}$

$\begin{array}{llllllllll}\text { Humerus } & 0.392 & 0.282 & 0.278 & 0.349 & 0.305 & 0.279 & 0.243 & 0.200\end{array}$

$\begin{array}{llllllllll}\text { Hip } & & 1.692 & 1.193 & 1.149 & 1.430 & 1.202 & 1.041 & 0.829 & 0.570\end{array}$

$\begin{array}{llllllllll}\text { Forearm } & & 0.011 & 0.007 & 0.007 & 0.009 & 0.008 & 0.007 & 0.006 & 0.004\end{array}$

fractures were not clinically apparent. The disutility occasioned by morphometric deformities outstripped that resulting from hip fracture, except from the age of 80 years onwards.

\section{Discussion}

In this paper we have characterised the risks and burden of vertebral fracture in Sweden using two definitions of vertebral fracture. The first is a clinically overt fracture from which we have previously made estimates for incidence and burden, albeit with different utility values [1]. In the present paper we additionally evaluated morphometric fractures, which include those vertebral deformities that do not come to clinical attention. The reason they are included is that they may still be of clinical significance. Firstly, they are of prognostic significance in that the risk of further fractures is significantly increased $[4,29]$. Thus, they are useful to consider in a case-finding strategy, for which purpose information on fracture probability is required. A second reason is that morphometric deformities not coming to clinical attention are not without symptoms [2,3]. It is difficult to be sure to what extent the decrement in quality of life associated with a clinically silent fracture is related to the fracture itself or to co-existing morbidity. For this reason we chose relatively conservative assumptions concerning the ongoing morbidity, so that the impact of their consideration is relatively modest in men. In women, nearly twice as many vertebral deformities are clinically covert than in men, so that the impact even of conservative estimates on disutility of nonclinical fractures is quantitatively greater.

In this paper we describe 10-year probabilities for vertebral fractures. Such data require documentation of the first fracture at a particular site. Second or subsequent fractures are common, particularly at the spine [10]. The overestimate from unadjusted data on vertebral fracture incidence is approximately $36 \%$ (see Table 2 ), so that the use of unadjusted data overestimates long-term risks. For this reason we used the incidence of first fracture. By contrast, long-term risks are underestimated when no account is taken of future mortality. For the 10year time span that we used in this paper, the effect is small, but the data are nevertheless adjusted.

It should be noted that the estimates of risk that we provide are modelled from measurements made at the femoral neck with BMD using DXA. The probabilities computed would differ from those derived from measurements made with other techniques or with the same technique, but at other sites. We also assume that the increase in risk of fracture is the same in women as in men. Though the data are scanty, the available evidence would suggest that this is so $[18,19,20,21,22]$.

A further limitation of these estimates is that they apply to a Swedish population and used data from Malmo, Sweden. For fractures other than vertebral fractures, data from Malmo appear to be representative for Sweden $[10,30]$. A strength of the use of Swedish data is the accuracy of information on fracture rates and on mortality. A disadvantage is that fracture rates are
Table 7 The proportion of fractures $(\%)$ due to vertebral, hip and other osteoporotic fractures by age, sex and the definition of vertebral fracture (left hand panels) compared with the burden (disutility adjusted incidence; right hand panels)

\begin{tabular}{|c|c|c|c|c|c|c|c|c|c|c|}
\hline \multirow[t]{3}{*}{ Sex } & \multirow{3}{*}{$\begin{array}{l}\text { Definition of } \\
\text { vertebral fracture }\end{array}$} & \multirow{3}{*}{$\begin{array}{l}\text { Site of } \\
\text { fracture }\end{array}$} & \multicolumn{8}{|c|}{ Age range (years) } \\
\hline & & & \multicolumn{4}{|c|}{ Incidence based } & \multicolumn{4}{|c|}{ Disutility based } \\
\hline & & & $50-54$ & $60-64$ & $70-74$ & $80-84$ & $50-54$ & $60-64$ & $70-74$ & $80-84$ \\
\hline \multirow[t]{3}{*}{ M } & \multirow[t]{3}{*}{ Clinical } & Spine & 18 & 22 & 17 & 10 & 51 & 44 & 30 & 18 \\
\hline & & Hip & 5 & 12 & 20 & 27 & 22 & 37 & 52 & 67 \\
\hline & & Other & 77 & 66 & 63 & 63 & 27 & 19 & 18 & 15 \\
\hline \multirow[t]{3}{*}{ M } & \multirow[t]{3}{*}{ Morphometric } & Spine & 34 & 40 & 33 & 22 & 68 & 61 & 48 & 32 \\
\hline & & Hip & 4 & 9 & 16 & 23 & 15 & 26 & 38 & 56 \\
\hline & & Other & 62 & 51 & 51 & 55 & 17 & 13 & 16 & 12 \\
\hline \multirow[t]{3}{*}{$\mathrm{F}$} & \multirow[t]{3}{*}{ Clinical } & Spine & 17 & 21 & 17 & 13 & 48 & 40 & 25 & 17 \\
\hline & & Hip & 4 & 11 & 22 & 37 & 16 & 33 & 50 & 65 \\
\hline & & Other & 79 & 68 & 61 & 50 & 36 & 27 & 25 & 18 \\
\hline \multirow[t]{3}{*}{$\mathrm{F}$} & \multirow[t]{3}{*}{ Morphometric } & Spine & 49 & 55 & 48 & 41 & 77 & 72 & 55 & 41 \\
\hline & & Hip & 2 & 6 & 14 & 25 & 7 & 15 & 30 & 46 \\
\hline & & Other & 49 & 39 & 38 & 34 & 16 & 13 & 15 & 13 \\
\hline
\end{tabular}


high and mortality is low compared to many other regions of the world. Thus, the probabilities we report are not necessarily applicable to other areas, particularly in the developing world. In addition, the pattern of probability with age may differ between countries. Short-term risks increase progressively with age until the short-term risk of death outstrips the fracture risk. Thereafter, the probability falls with age. For 10-year probabilities this break point occurred at the age of 75 to 85 years, but would occur sooner in countries with a higher mortality.

A significant finding from the present study is the high morbidity consequences of vertebral fractures arising from the high utility losses. Quality of life was measured throughout the 1st year following a clinical vertebral fracture to assess quality-adjusted life years (QALYs). With this technique health states are valued between 0 (death or the worst health state imaginable) and 1 (perfect health). The loss of utility in the 1st year after vertebral fracture was $37 \%$ that of an individual in perfect health. This estimate is markedly greater than those previously used by ourselves and by the National Osteoporosis Foundation [1, 26]. These estimates $(5 \%$ utility loss) were based on expert opinion in the absence of empirical data. Subsequent studies, including our own, have shown these losses to be seriously underestimated $[5,6,7,8]$. The validity of our findings is further supported by the health state values we derived in the same study for hip fracture and for forearm fracture, which are very close to other empirical estimates $[31,32$, 33].

It may be relevant that these health states were taken from patients originally attending the orthopaedic department and may not be representative of all clinically overt fractures. Comparison of the incidence rates over all clinically evident fractures (Malmo 1993-1994) and hospitalised fractures (Swedish patient register 1996) suggests that approximately $25 \%$ of men and women are hospitalised. In the patients in whom we assessed quality of life, $42 \%$ were hospitalised, suggesting that bias cannot be excluded.

The high morbidity from clinical vertebral fractures is most marked in the first 6 months after the fracture event and thereafter attenuated with time similar to observations of Tosteson et al. [8]. Nevertheless, the utility loss in the 1st year was at least as great as that noted for hip fracture. In subsequent years we assumed that utility loss diminished in keeping with other observations that studied patients well after fracture events $[8,25]$. Thus, when utility loss was cumulated over remaining life-time, disutility was less than for hip fracture, since the impairment of quality of life is more marked in 2nd and subsequent years for hip fracture compared to clinical vertebral fracture. At the age of 50 years the disutility from clinical vertebral fracture was 1.053 in women compared with 1.692 for hip fracture (see Table 6). Thus, a clinical vertebral fracture occasions $62 \%$ of the morbidity expected from a hip fracture at that age. In an earlier study where the NOF estimates of utility loss were used [26], we estimated that the utility loss from a clinical vertebral fracture was only $24 \%$ that of a hip fracture [1].

Greater uncertainties surround the disutility associated with clinically silent fractures, since a greater proportion of the utility loss computed may be related to pre-existing comorbidity compared to clinical fractures. The disutility assumed is, however, modest and has a small impact on the expected disutility at any age. For example, in women aged 50 years the average utility loss from a clinical spine fracture was 1.053 and 0.857 for all vertebral fractures combined (see Table 6). Since costs of asymptomatic morphometric fractures are also likely to be lower than for clinical fractures, the consideration of all fractures or clinical fractures in health economic analysis is likely to have little impact on estimates of cost effectiveness and thus on intervention thresholds.

The undervaluation of vertebral fracture morbidity compared to that of a hip fracture has consequences for practice guidelines that are based on health economic assessment. Hip fractures occur most often in advanced age and intervention becomes more cost-effective, therefore, with advancing age. Vertebral fractures (and other osteoporotic fractures) by contrast occur earlier in the natural history of osteoporosis. The omission of these fractures or undervaluation of the morbidity in turn undervalues the cost-effectiveness of interventions, particularly in younger patients with osteoporosis. Thus, higher intervention thresholds arise if health economic estimates are made on hip fracture risk alone, particularly in younger individuals.

We conclude that the morbidity arising from vertebral fractures has been considerably underestimated using values derived from expert opinion. Empirical data suggest a very substantial impact of clinical vertebral fractures that incur a disability that is approximately $62 \%$ of that incurred by a hip fracture over the remaining lifetime of individuals. The large societal impact, particularly in mid-life, needs to be accounted for in health economic strategies for osteoporosis.

Acknowledgements We are grateful to the International Osteoporosis Foundation, the International Society for Clinical Densitometry, the Alliance for Better Bone Health, Hologic, IGEA, Lilly, Lunar, Novartis, Pfizer, Roche and Wyeth for their unrestricted support of these studies.

\section{References}

1. Kanis JA, Oden A, Johnell O, Jonsson B, De Laet C, Dawson A (2002) The burden of osteoporotic fractures: a method for setting intervention thresholds. Osteoporos Int 12:417-427

2. Nevitt MC, Ettinger B, Black DM, Stone K, Jamal SA, Ensrud K, Segal M, Genant HK, Cummings SR (1998) The association of radiographically detected vertebral fractures with back pain and function. A prospective study. Ann Intern Med 128:793800

3. Nevitt MC, Thompson DE, Black DM, Rubin SR, Ensrud K, Yates AJ, Cummings SR (2000) Effect of alendronate on 
limited-activity days and bed-disability days caused by back pain in postmenopausal women with existing vertebral fractures. Arch Intern Med 160:77-85

4. Lindsay RL, Silverman SL, Cooper C, Hanley DA, Barton I, Broy SB, Licata A, Benhamou L, Geusens P, Flowers K, Stracke H, Seeman E (2001) Risk for new vertebral fracture in the year following a fracture. JAMA 285:320-323

5. Merlino LA, Bagchi I, Taylor TN, Utrie P, Chrischilles E, Sumner W, Mudano A, Saag KG (2001) Preferences for fractures and other glucocorticoid-associated adverse events among rheumatoid arthritis patients. Med Decis Making 21:122-132

6. Gabriel SE, Kneeland T, Melton LJ, et al (1999) Health-related quality of life in economic evaluations for osteoporosis: whose values should we use? Med Decis Making 19:141-148

7. Zethraeus N, Borgstrom F, Johnell O, Kanis JA, Jonsson B (2002) Costs and quality of life associated with osteoporosisrelated fractures: results of a Swedish Survey. Working paper series in economics and finance. Report 512. School of Health Economics, Stockholm

8. Tosteson ANA, Gabriel SE, Grove MR, Moncur MM, Kneeland TS, Melton LJ (2001) Impact of hip and vertebral fractures on quality adjusted life years. Osteoporos Int 12:10421049

9. Johnell O, Kanis JA, De Laet C, Jonsson B, Zethraeus N, Oden A (2002) Sequential changes in quality of life after osteoporotic fractures. Osteoporos Int 13 [Suppl 1]:S70

10. Kanis JA, Johnell O, Oden A, Sernbo I, Redlund-Johnell I, Dawson A, De Laet C, Jonsson B (2000) Long-term risk of osteoporotic fracture in Malmo. Osteoporos Int 11:669-674

11. Felsenberg D, Silman AJ, Lunt M, Armbrecht G, Ismail AA, Finn JC, et al (2002) Incidence of vertebral fracture in Europe: results from the European Prospective Osteoporosis Study (EPOS). J Bone Miner Res 17:716-724

12. Van der Klift M, De Laet CEDH, McCloskey EV, Hofman A, Pols HAP (2002) The incidence of vertebral fractures in men and women: The Rotterdam Study. J Bone Miner Res 17:10511056

13. McCloskey EV, Spector T, Eyres KS, Fern DE, O'Rourke N, Vasikaran S, Kanis JA (1993) Definition of vertebral deformity - a semi-automated method for use in population studies and clinical trials. Osteoporos Int 3:138-147

14. Kanis JA, Johnell O, Oden A, Dawson A, DeLaet C, Jonsson B (2001) Ten year probabilities of osteoporotic fractures according to BMD and diagnostic thresholds. Osteoporos Int 12:989-995

15. Kanis JA, Johnell O, Oden A, De Laet C, Jonsson B, Dawson A (2002) Ten year risk of osteoporotic fracture and the effect of risk factors on screening strategies. Bone 30:251-258

16. Looker AC, Orwoll ES, Johnston CC, Lindsay RL, Wahner HW, Dunn WL, Calvo MS, Narris TB, Neyse SP (1997) Prevalence of low femoral bone density in older US adults from NHANES III. J Bone Miner Res 12:1761-1768

17. World Health Organisation (1994) Assessment of fracture risk and its application to screening for postmenopausal osteoporosis. WHO Technical Report Series 843. WHO, Geneva
18. Lunt M, Felsenberg D, Reeve J, Benevolenskaya L, Cannata J, Dequeker J (1997) Bone density variation and its effect on risk of vertebral deformity in men and women studied in 13 European centres: the EVOS study. J Bone Miner Res 12:18831894

19. Kanis JA, Glüer C-C (2000) An update on the diagnosis and assessment of osteoporosis. Osteoporos Int 11:192-202

20. De Laet CEDH, Van Hout BA, Burger H, Hofman A, Pols HAP (1997) Bone density and risk of hip fracture in men and women: cross sectional analysis. Br Med J 315:221-225

21. De Laet CEDH, Van Hout BA, Burger H, Hofman A, Weel AEAM, Pols HAP (1998) Hip fracture prediction in elderly men and women: validation of the Rotterdam study. J Bone Miner Res 13:1587-1593

22. Wasnich RD, Ross PD, Heilbrun LK, Vogel JM (1985) Prediction of postmenopausal fracture risk with use of bone mineral measurements. Am J Obst Gynaec 153:745-751

23. Marshall D, Johnell O, Weder H (1996) Meta-analysis of how well measures of bone mineral density predict occurrence of osteoporosis fractures. Br Med J 312:1254-1259

24. Lundberg L, Johannesson M, Isacson DGL, Borgquist L (1999) Health-state utilities in a general population in relation to age, gender and socio-economic factors. Europ J Public Health 9 211-217

25. Oleksik A, Lips P, Dawson A, et al (2000) Health-related quality of life in postmenopausal women with low BMD with or without prevalent vertebral fracture. J Bone Min Res 15:1384-1392

26. National Osteoporosis Foundation (1998) Osteoporosis: review of the evidence for prevention, diagnosis and treatment and cost-effectiveness analysis. Status report. Osteoporos Int $8: 1-88$

27. Jonsson B, Christiansen C, Johnell O, Hedbrandt J, Karlsson R (1996) Cost effectiveness of fracture prevention in established osteoporosis. Scand J Rheumatol [Suppl] 103:30-38

28. Jonsson B, Kanis JA, Dawson A, Oden A, Johnell O (1999) Effect and offset of effect of treatments for hip fracture on health outcomes. Osteoporos Int 10:193-199

29. Johnell O, Oden A, Caulin F, Kanis JA (2001) Acute and longterm increase in fracture risk after hospitalisation for vertebral fracture. Osteoporos Int 12:207-214

30. Bengner U, Johnell O (1985) Increasing incidence of forearm fractures. A comparison of epidemiological patterns 25 years apart. Acta Orthop Scand 56:158-160

31. Kanis JA, Brazier J, Stevenson M, Calvert N, Lloyd-Jones M (2002) Treatment of established osteoporosis. A systematic review and cost-utility analysis. Health Technol Assess 6:29

32. Dolan P, Torgerson D, Kakarlapudi TK (1999) Health-related quality of life of Colles' fracture patients. Osteoporos Int 9:196-199

33. Brazier JE, Green C, Kanis JA (2002) On behalf of the Committee of Scientific Advisors, International Osteoporosis Foundation. A systematic review of health state utility values for osteoporosis-related conditions. Osteoporos Int $13: 768-777$ 